\title{
EDITH STEIN: UMA ANTROPOLOGIA INTEGRAL COMO FUNDAMENTO PEDAGÓGICO
}

EDITH STEIN: UNA ANTROPOLOGÍA INTEGRAL COMO FUNDAMENTO PEDAGÓGICO

Vitor Vinicios da Silva*

\section{RESUMO}

A comunicação está descrita de forma única, em que percorreremos o contexto da pensadora, as problemáticas de seu tempo, o método fenomenológico como caminho para entender o que é o homem e, por fim, a sua antropologia como resposta a uma civilização ocidental que, segundo Stein, é obscura e de terrenos inférteis que impede o homem de desenvolver suas potencialidades, tornando-os "homens atrofiados". A presente comunicação se baseou em pesquisa bibliográfica analítica da obra Der Aufbau der menschlichen Person (A estrutura da pessoa humana), como obra básica e, ao mesmo tempo, complementada com leituras de comentadores e de outros filósofos que ajudam a entender o pensamento da filósofa. Levando em consideração que a obra de Edith Stein é escassa na língua portuguesa, optou-se em consultar a bibliografia steniana predominantemente em espanhol, com referências a seus títulos em original.

PALAVRAS-CHAVE: Edith Stein. Fenomenologia. Antropologia. Pessoa humana. Pensamento ocidental.

\section{ESUMEN}

La comunicación está descrita de forma única, en que recorreremos el contexto de la pensadora, las problemáticas de su tiempo, el método fenomenológico como camino para entender lo que es el hombre y, por fin, su antropología como respuesta a una civilización occidental que, según Stein, es oscura y de terrenos infértiles que impide al hombre de desarrollar sus potencialidades, haciéndolos "hombres atrofiados". La presente comunicación se basó en la investigación bibliográfica analítica de la obra Der Aufbau der menschlichen Person (La estructura de la persona humana), como obra básica y, al mismo tiempo, complementada con lecturas de comentaristas y de otros filósofos que ayudan a entender el pensamiento de la filósofa. Teniendo en cuenta que la obra de Edith Stein es escasa en portugués, se decidió consultar al steniana bibliografía predominantemente en español, con referencias a sus títulos originales.

PALABRAS CLAVE: Edith Stein. La fenomenología. Antropología. Persona humana. Pensamiento occidental.

\footnotetext{
* Graduando em filosofia pelo Instituto Santo Tomás de Aquino, BH. E-mail: vitorvinicios916@ gmail.com.
} 
É notório que a busca por entender o homem foi e ainda é um dos grandes crivos da filosofia. Essa busca por entender o homem é entendida como antropologia, seja ela filosófica ou teológica. Entender o homem não é apenas um mero prestígio ou algo semelhante, mas entendê-lo é responder o que ele é, o que deve ser e como deve agir. Dessa maneira, imersos num terreno de incertezas e desafios, em que nossa esperança é fragilizada pelos diferentes impasses que enfrentamos, apresentarei a antropologia, segundo o pensamento da filosofa Edith Stein (1891 -1942), como resposta e caminho aos grandes desafios da nossa atualidade.

Como metodologia apresentaremos de forma dedutiva o contexto e o pensamento steniano. A comunicação está descrita de forma única, em que percorreremos o contexto da pensadora, as problemáticas de seu tempo, o método fenomenológico como caminho para entender o que é o homem e, por fim, a sua antropologia como resposta a uma civilização ocidental que, segundo Stein, é obscura e de terrenos inférteis que impede o homem de desenvolver suas potencialidades, tornando-os "homens atrofiados" (STEIN, 1998, p. 140).

A presente comunicação se baseou em pesquisa bibliográfica analítica da obra Der Aufbau der menschlichen Person (A estrutura da pessoa humana), como obra básica e, ao mesmo tempo, complementada com leituras de comentadores e de outros filósofos que ajudam a entender o pensamento da filósofa. Levando em consideração que a obra de Edith Stein é escassa na língua portuguesa, optou-se em consultar a bibliografia steniana predominantemente em espanhol, com referências a seus títulos em original, alemão.

É patente que o pensamento moderno é conhecido, convencionalmente, entre os séculos XVII - XIX (MARCONDES, 1997, p. 139). Pensamento esse que desponta como um novo projeto ocidental, em que se manifesta uma nova ideia de autonomia interpretativa, de atribuição de valores aos objetos ou fenômenos que lhe toca a sensibilidade, e outras mais. Esse novo edifício moderno, no sentido histórico-filosófico, nos remete ordinariamente a uma ideia de filosofia moderna, o período em que se inicia depois do Renascimento, a partir do século XVII. O moderno ou a modernidade começa a ser associada há um arcabouço de termos, assumindo uma identidade subjetiva tendo em vista um novo projeto para a humanidade, que consiste num significado positivo (ABBAGNANO, 2012, p. 791).

Todavia, esse termo assenta-se em terreno riscoso, em termos vagos, pois é, ao mesmo tempo, complexo e possui uma gama de sentidos, não conseguindo, assim, abarcar seu significado por inteiro. Desse modo, não temos a pretensão de perscrutar todas as suas definições e indefinições. Nosso objetivo é apresentar nosso maior escopo que é a antropologia steniana, ou seja, uma resposta aos grandes desafios que a modernidade 
promoveu como, por exemplo, a perda do telos humano, o aniquilamento da alteridade e outros mais.

Intrínseco a esse novo projeto moderno houve-se uma ruptura de um mundo heterônomo (visão normativa - o mundo da Phisys dos gregos permeado por uma ordem geométrica invariável) para um mundo autônomo (não necessita de um fundamento último - o próprio homem é o fundamento (SOUZA, 2005). Assim, torna-se como ideia central da modernidade o progresso da razão, em outras palavras, a convicção de que a razão o levará a uma resignação do mundo e do ser. Dessa maneira, há uma negação do telos das coisas, em que não existe mais um fim, mas há um desligamento desse pensamento à medida que a ciência progride.

Todavia, a casualidade final passa por um rigoroso exame crítico na idade moderna. Existe uma espécie de indeterminação do fim ou telos das coisas. Assim, se desejamos obter a certeza do conhecimento, é preciso que nos livremos dos fins e, consequentemente, abandonemos a questão do bem. Quanto mais a ciência moderna se desenvolveu, mais o homem foi cortando seus laços com a filosofia e com a teologia. (SOUZA, 2005, p. 85)

Entusiasmado por todo esse pensamento moderno ergue-se sobre o pensamento ocidental as novas ciências. Dentre estas, duas correntes tiveram como fito o fundamento de todo o saber científico: a filosofia positivista, cunhada e desenvolvida pelo pensador Isidore Auguste-Marie-Xavier Comte (1798-1857) que presumia fazer uma revolução no pensamento ocidental, e a denominada psicologia experimental. Esta sofre influência do empirismo quando reconhece que o intelecto só pode conhecer o mundo que nos cerca através das sensações do corpo que se transformará em sensações da mente, sendo esta conhecida como psicologismo.

Tanto uma quanto a outra são frutos de uma grande transformação ocorrida no decurso do pensamento ocidental. Essa transformação será conhecida como Revolução científica, isto é, o momento em que a ciência deixa de ser contemplativa, ciência dos antigos, para se tornar uma ciência ativa, dos modernos.

Assim, temos no século XIX o triunfo do cientificismo, que reconhece apenas a natureza material, ou seja, está embasado na certeza rigorosa dos fatos. Além do que, se reconhecesse como a única fonte explicável do mundo, seja ele dos valores ou dos fatos. Mas, a grande novidade dessa corrente vai mais além, pois postula a crença de submeter todo o conhecimento humano às leis desse novo método. 
Em meio à efervescência dessas novas ciências a pensadora alemã Edith Stein. (1891 1942) se inquietou com o esteio do pensamento moderno, isto é, as visões que se formaram a partir das novas ciências modernas, mais especificamente com as visões antropológicas. Essas antropologias, segundo a pensadora, são dadas como insuficientes, pois não são capazes de abarcar o homem na sua total complexidade. Por longos anos, segundo Stein, a palavra antropologia foi relacionada como parte de uma ciência natural, sendo vista como uma ciência auxiliadora da medicina, que é uma ciência que "estudia al hombre como espécie, al igual que la zoologia estudia las espécies animales" (STEIN,1998, p. 31). Assim, a antropologia natural, a priori, criou uma imagem descritiva do homem, isto é, a estrutura do corpo humano, suas funções e suas peculiaridades. Logo, determinando o homem numa unidade, dita como espécie, passa-se a investigar, na multiplicidade de homens, a sua diferença entre os muitos. Após essa visão morfológica passou-se a uma visão histórica e evolutiva do homem, em que são analisadas as leis universais e o processo de evolução do homem, que busca determinar quando o homem surgiu no solo terrestre. Contudo, essa antropologia da ciência natural não é o fundamento pedagógico que Stein procura para seu pensamento. Stein (1998, p. 33), reconhece a validade de se "conocer la estrutura, las funciones y las leyes evolutivas del cuerpo humano" e do "conocimiento de los grupos humanos, de los pueblos, e etc. Porém essas antropologias não conseguem servir de fundamento para uma pedagogia steniana, por dois motivos: o primeiro é que a antropologia natural ocupa-se do indivíduo como um exemplar da espécie humana, ou seja, não vê sua característica individual, assim, é inevitável obter uma mal interpretação do homem. O educador deve tratar o "indivíduo como este hombre con su irrepetible modo de ser próprio, y no como ejemplar de um tipo" (STEIN, 1998, p. 34), já o outro ponto é que a antropologia não deve ter obrigação apenas com o indivíduo, mas com as "unidades suprapersonales" (STEIN, 1998), ou seja, tribos, povos, pois cada homem concreto pertence a uma dessas unidades. Mas, como já visto nas ciências naturais não existe essa obrigação.

Para a filósofa, há formulação de uma ideia reducionista do ser humano, ele é visto apenas como um mero objeto para as ciências naturais. Nessa ótica, "os sentimentos complexos de sensações orgânicas, o que equivale a considerar as vivências de consciência do sujeito, são dadas como efeito de causas materiais" (RUS, 2015, p. 28), assim, denominou-se como uma visão reducionista do ser humano, pois o delimita à apenas uma dimensão. Frente a esse pensamento, Stein nos convida a retomarmos uma das mais altas indagações filosóficas: O que é o homem? O que o distingue dos demais seres vivos? Para, assim, resgatar e conhecer 
o telos a que se orienta sua natureza e criar respostas para tal e, dessa maneira, apontar novos caminhos ou alternativas para sanar uma cultura de intolerância e da negação da alteridade.

Tendo já um fim, Edith Stein necessita de um caminho para chegar à resposta que tanto procura. Ao mesmo tempo, há conjuntamente com essas novas ciências uma florescência de novos pensadores e correntes filosóficas que, não muito diferente da pensadora, buscam novos caminhos a serem seguidos. Dessas várias correntes, apresentam-se o Racionalismo (Descartes 1546-1650, Leibniz 1646-1716), o Empirismo (Locke 1632-1704), o Idealismo alemão (Fichte 1762-1814) e a Escola Fenomenológica com o filósofo Edmund Husserl (1859-1938), que como um grande admirador das ciências exatas procurou fazer da filosofia uma "ciência rigorosa, colocando como tarefa a busca por uma nova fundamentação última da filosofia" (HUSSERL, 2002, p. 19), decisiva para o futuro.

Em conformidade com esse mesmo pensamento, Stein torna-se aluna do filósofo Husserl, elegendo, assim, seu Método Fenomenológico como caminho para responder sua maior indagação. Ao eleger o caminho, afirma: "El método con el cual trataré de solucionar los problemas es el fenomenológico. Es decir, el método que E. Husserl elaboró y empleó por primeira vez em tomo II de sus Investigaciones lógicas. ” (STEIN, 1998, p. 49). Assim, a filósofa toca no âmago da questão ao ir além de seu mestre, pois entende o método de uma forma singular, ou seja, acredita que o ser humano não se pode reduzir a apenas ao plano gnosiológico, pois o "eu” é um "eu” que vive, que sente, que pensa, ou seja, é cercado de experiências.

Dessa maneira, contrariamente à tendência de Husserl de fazer abstração de tudo que há de concreto e de pessoal, Stein na sua reflexão não "fixa apenas no Eu puro, mas mostra-se intensamente atenta à profundidade do sujeito tal como ele se experimenta e se vivencia realmente no interior" (RUS, 2015, p. 30). Dado esse novo método filosófico denominado como fenomenologia, formamos terreno para nosso fito primordial que é a antropologia steniana.

É fato que as antropologias construídas até então, segundo Stein, não abarcam a profundidade do ser humano, caindo, assim, na superficialidade. Todas essas visões de homem construídas pelas ciências naturais, isto é, a visão de homem no idealismo alemão, na psicologia experimental, no positivismo, enfim, todas elas cometem o equívoco de reduzir o homem apenas a tipos morfológicos, históricos e evolutivos, que culminam numa classificação de raças, tribos e outros. Enquadrando também nesse âmbito há uma crítica da filosofa direcionada à visão de homem na filosofia de Heidegger que, segundo Edith Stein, 
não há um fim a não ser o ser mesmo, permanecendo-se no nada. “[...] Pero no le há sido señalado ningún outro fin que ser él mismo y perseverar en la nada de su ser" (STEIN, 1998, p. 13). Com efeito, para a pensadora há uma insuficiência nas antropologias que tomam como base as ciências naturais, pois há “[...] uma visão racionalista, levando em conta apenas o desenvolvimento intelectual da pessoa, reduzindo ou mutilando justamente o terreno da experiência pessoal", conforme observa Zille (2017, p. 372).

A grande indagação de Edith Stein é: "Esta Ciência natural, Morfológico-descriptiva y causal-explicativa? es acaso la antropologia que buscamos como fundamento de la pedagodia? (STEIN, 1998, p. 32). Não, pois segundo ela

\footnotetext{
[...] una antropologia que proceda conforme al método de la ciência natural no puede responder. Pues para decidir qué atención merecem el indivíduo, la raza y la humanidade em sus relaciones mutuas es preciso um critério valorativo. (STEIN, 1998, p. 35).
}

Diante de todas essas antropologias, Stein percebe o limite do conhecimento que tem como base o mundo material, ou seja, que caminha (método) por meio das leis universais não sendo, assim, fiel às peculiaridades de cada indivíduo. A grande indagação feita pela filósofa "existe realmente una vía de conocimento que conduzca a la captación de la individualidade [...]" (STEIN, 1998, p. 37).

Stein, em busca dessa resposta, chega a uma antropologia do espírito, "una ciencia del hombre como persona espiritual [...] que estudia la estructura de todas las realidades espirituales, como son la comunidade, el Estado, el Derecho, etc. Esta antropologia es de outra índole que la científico - natural de la que partimos" (STEIN, 1998, p. 41).

Essa visão antropológica de Stein é integral, compreendida num todo em três extratos: corpo, psique e espírito, que estão intimamente ligados. Assim sendo, fazer-se cego para essa tripartição-unitária é cair na mesmice das ciências naturais.

Dentro dessa ótica, ela constrói sua antropologia que nos leva a compreender a individualidade humana; e outras palavras, o indivíduo na sua singularidade. Já embrenhados no pensamento steniano, apontemos sua concepção de pessoa humana como um ser constituído unitariamente por esses três extratos, "o que já havia sido constatada pelos filósofos gregos, principalmente por Platão e Aristóteles” (ZILLES, 2017, p. 371).

Como já dito, a pensadora compreende o homem composto por uma estrutura, composta por corpo, alma (psique) e espírito. O homem como corpo é visto como tudo e qualquer matéria que existe, não sendo, num primeiro momento, diferente das outras matérias 
que aparecem. Desse modo, conhecemos o homem por meio daquilo que se expressa como característica externa, quer dizer, altura, cor dos olhos, cabelo e outros, "por su constitucíon corporal el hombre es una cosa material como cualquier outra, está sometido a las mismas leyes y está inscrito en el marco de la naturaleza material” (STEIN, 1998, p. 51).

Porém, o homem extrapola essa dimensão apenas material, pois não é um corpo qualquer como os demais, isto é, não o vemos como apenas um corpo material semelhante a uma pedra, por exemplo, mas é algo também vivo, em que, pode mover-se, sentir e mais. Assim, vemo-lo como “corpo físico (körper) e como corpo próprio/vivenciado (Leib) os quais compõem a dimensão material" (ALFIERE, 2014, p. 63).

Já no extrato da "psique tanto o animal como o ser humano têm uma vida psíquica" (ALFIERE, 2014, p. 67). O animal sente prazer e desprazer, o homem também, o animal sente dor e o homem também, desse jeito, tanto o homem como o animal são permeados por comportamentos psíquicos. Esses atos podemos denominar como "impulso, dos instintos e das reações" (ALES BELLO, 2006, p. 39), que são as sensações e emoções, tanto da alma humana como da alma animal. E é válido aqui identificarmos que ter alma para Edith Stein:

quiere decir poser un centro interior, em el que se percebe como entrechoca todo lo que viene de fuera, y del que procede cuando se manifiesta em la conducta del cuerpo com proveniente de dentro. Se trata de um punto de intercambio, em que impactan los estímulos u del que salen las respuestas. (STEIN, 1998, p. 81).

Mas, o ser humano se distingue dos demais animais, pois não tem apenas uma abertura sensitiva. O homem não é submisso às manifestações psíquicas, encontramos na alma humana qualidade acima da dimensão psíquica, ou seja, potencialidades. "Encontremos na alma humana outras qualidades que completem a descrição da sua especificidade" (ALFIERE, 2014, p. 67). Trata-se do espírito, o homem se difere, dos demais animais, no âmbito do espírito, porém devemos expurgar de nossa compreensão a conotação religiosa do termo, visto que espírito é aquilo que "ordena el material sensible en una estructura y, al hacerlo, penetra con su mirada en el interior de um mundo de objetos, se denomina entendimento, o intelecto" (STEIN, 1998, p. 146).

É esse extrato que possibilita à pessoa humana ser capaz de refletir e de mudar de direção; em outras palavras, ser um anímico espiritual. Esse é o lugar onde o núcleo descansa, tem seu lugar próprio, e é nesse lugar que a pessoa humana deve adentrar para tomar decisões, refletir, é o lugar de encontrar-se por inteiro: "Solamente desde él puede el alma adoptar 
decisiones importantes, tomar partido por algo o hacer donación de sí misma" (STEIN, 1998, p. 155).

O espírito, para Stein, é aquele que ordena a matéria, é aquele que com sua vida intencional mira a matéria a partir da sua primeira atividade que é a percepção sensível. Edith Stein denomina o espírito como "entendimento, o intelecto" (STEIN, 1998, p. 146), é aquele que é capaz de experimentar tudo aquilo que provém da vida material. Com o espírito o ser humano é capaz de apreender o fenômeno que parece dar possibilidade ao indivíduo e liberdade de escolha.

Nessa compreensão é necessário clarificarmos a intrínseca ligação entre ser humano e educação (ou pedagogia), pois como dito acima, Stein buscava uma antropologia que fosse fundamento para pedagogia. A ideia de ser humano proposta pela autora é fundamento para o labor educativo, ou seja, para a ciência da educação. Esse pensamento é por uma razão bastante simples: "a educação é aquilo que põe em marcha, de maneira exemplar, a edificação da pessoa e a manifestação do seu sentido de seu ser" (RUS, 2015, p. 31). Ao falarmos de educação referimos a "[...] formação dos seres humanos e pressupomos um certo modelo ou ideal a construir seu lugar no mundo.” (ZILLES, 2017, p. 370). Dessa maneira, a imagem de homem que construímos é crucial para sua formação, ou seja, para sua construção de valores e atuação no mundo em que vive. Assim, afirma Zilles:

\footnotetext{
O ideal de humanidade, para a pedagoga Edith Stein, representa uma meta à qual pretende conduzir o educando, despertando e desenvolvendo suas energias individuais, em busca de seu lugar no seu povo e na humanidade, para contribuir na criação do espírito e da cultura. (ZILLES, 2017, p. 374).
}

Nessa perspectiva entender o ser humano nos leva, consequentemente, a entender o terreno em que ele se situa o mesmo nos dias atuais. Ora, os desafios que batem à nossa porta são derivações de um processo de constituição do ser humano, do seu processo educacional. Pretender sanar os desafios atuais é, indubitavelmente, voltar o olhar para o terreno em que o ser humano se forma. O desenvolvimento da pessoa humana depende das condições externas que o permeiam, pois é aquilo que podemos entender como alimento ou estímulo humano, ou seja, são fatores que auxiliam no desenvolvimento. São as denominadas condições ou estímulo para o desenvolvimento interno e externo da pessoa. A semelhança de Edith Stein é "uma relação de estímulo - respostas" (STEIN, 1998, p. 139). Em outras palavras, "en el desarrollo orgânico, las condiciones materiales - suelo, clima, etc, - son determinates, junto a otros factores, para la concreción de la forma. (STEIN, 1998, p. 139). 
Para responder à pluridiversidade cultural apontamos para o pensamento da filosofa e teóloga Edith Stein, segundo a qual, é necessário retomarmos esse telos da humanidade, dado que todos os seres humanos têm as mesmas raízes, se dirigem a um mesmo fim e estão implicados nesse mesmo telos. Além disso, os seres humanos têm uma copertença que transcende o tempo e espaço, diferentemente dos animais. O ser humano, distintivamente dos animais, não está pré-determinado, tem uma múltipla possibilidade de ser. Logo, podemos afirmar que essa grande indagação: o que é o ser humano? é o grande eixo que constitui toda a obra steniana e que nos leva a compreender as múltiplas formas de violências que imperam non dias atuais.

É imperativo que busquemos novas portas para responder os gritos que ecoam na sociedade moderna. Necessitamos de um labor educativo que estimule a aceitação, ou melhor, a copertença da alteridade na comunidade. Formarmos seres humanos numa perspectiva intolerante é torná-los seres vivos atrofiados, como nos indica Stein:

Los perros mansos y los gatos que viven encerrados em uma casa y reciben su comida sin tener que buscarla por si mismo, no pueden expressar sus instintos de animales de presa. De igual manera, las capacidades del hombre que no encuentran ocasión para actualizarse pueden quedar atrofiadas. (STEIN, 1998, p. 140).

Por conseguinte, é tarefa também da antropologia, embasada no espirito, se perguntar "en que relación se encuentra el hombre individual com las coletividades a las que pertenece" (STEIN, 1998, p. 42). Assim, a filósofa alemã acredita que a "organização que respeite a pessoa e permita que se torne seres íntegros seja a comunidade” (BELLO, 2006, p. 73). Essa comunidade é caracterizada por assumir responsabilidades recíprocas, ou seja, almejando um mesmo fim num projeto em comum. Nesse contexto de comunidade podemos ver um projeto em comum a partir de uma união de pessoas, que respeita a individualidade de cada um, “[...] como um lugar de movimento individual e, assim, de construção de uma nova personalidade que é a comunidade" (BELLO, 2006, p. 72). Sendo assim, é nesse viés que podemos construir um terreno fértil, em que se respeite a diferença na cor, no gênero, na etnia, na orientação sexual, na religião, na cultura e na posição política.

Portanto, mergulhados nesse imenso terreno de incertezas e desafios, em que nossa esperança é fragilizada pelos diferentes impasses que enfrentamos, a contribuição de Edith Stein se torna extremamente preciosa, pois busca entender o que nós somos, o que devemos ser e como devemos agir. Além disso, faz-se uma nova luz em meio aos tempos obscuros 
vivenciados na atualidade; com base na antropologia integral steniana somos capazes de construir relações mais humanizastes e mudar o curso da humanidade.

A educação é a arte suprema cujo material não é nem a madeira nem a pedra, mas a alma humana [...] É vida interior que é o fundamento último; a formação se faz do interior para o exterior. (Edith Stein).

\section{REFERÊNCIAS}

ALES BELLO, Angela. Introdução à fenomenologia. Bauru, São Paulo: Edusc, 2006.

ALFIERE, Francesco. Pessoa humana e singularidade em Edith Stein: uma nova fundação da antropologia filosófica. São Paulo: Perspectiva, 2014.

HUSSERL, Edmund. A crise da humanidade europeia e a filosofia. 2. ed. Porto Alegre: EDIPUCRS,2002.

MAHFOUD, Miguel; SAVIAN, Juvenal F. (org.). Diálogos com Edith: filosofia, psicologia, educação. São Paulo: Paulus, 2017.

MARCONDES, Danilo. Iniciação à história da filosofia: dos pré-socráticos a Wittgenstein. Rio de Janeiro: Jorge Zahar, 1997.

RUS, Éric de. A visão educativa de Edith Stein: aproximação a um gesto antropológico integral. Belo Horizonte: Ed. Artesã, 2015.

SOUZA, José C. Aguiar de. O projeto da modernidade: autonomia, secularização e novas perspectivas. Brasília: Liber Livro Editora, 2005.

STEIN, Edith. La estructura de la persona humana. Madrid: BAC,1998. 